\title{
ABUNDANCE OF CORAL FISH SPECIES AND THE CONDITION OF CORAL REEFS IN THE WATERS OF THE TIKUS ISLAND, BENGKULU CITY
}

\author{
Almaarif Paniska ${ }^{*}$, Joko Samiaji ${ }^{2}$, Thamrin ${ }^{2}$ \\ ${ }^{1}$ Student of The Faculty of Fisheries and Marine Science University of Riau, Pekanbaru \\ ${ }^{2}$ Lecturer at The Faculty of Fisheries and Marine Science University of Riau, Pekanbaru \\ *paniskaalmaarif1906@gmail.com
}

\begin{abstract}
Coral reefs are one of the ecosystems that have ecological functions for marine life, one of which is reef fish. Coral fish are marine biota that live in association with coral reefs. This study aims to determine the abundance of reef fish, the condition of coral reefs and the relationship between abundance of reef fish and coral reefs. This research was conducted in June 2019 in the waters of Tikus Island, Bengkulu City. The method used is a survey method. Data collection on reef fish was carried out using the Underwater Visual Census (UVC) method and coral reefs condition data colletion is done using the Line Intercept Transect (LIT) method. The abundance of reef fish found at the study site averages in the abundant category. At station I, an abundance of reef fish was $2,18 \mathrm{ind} / \mathrm{m}^{2}$, at station II it was 4,18 $\mathrm{ind} / \mathrm{m}^{2}$, and at station III it was $1,27 \mathrm{ind} / \mathrm{m}^{2}$. While the average condition of coral reefs at the study site is include in the medium category. At station I, the percentage of live coral cover was $39,30 \%$ or include in the medium category. At station II, the percentage of live coral cover was $50,94 \%$ or include in the good category. And at station III, the percentage of live coral cover was $46,32 \%$ or include in the medium category. Coral fish and coral reefs have a fairly close relationship. Reef fish use coral reefs as a place to find food, shelter and spawn or breed.
\end{abstract}

Keywords: Reef fish, Coral reefs, Tikus Island

\section{PENDAHULUAN}

Terumbu karang merupakan salah satu ekosistem yang secara ekologi memiliki fungsi besar bagi ekosistem laut baik secara ekologis maupun ekonomis. Menurut Burhanuddin (2011) dikemukakan bahwa ekosistem terumbu karang selain memiliki fungsi ekologis sebagai penyedia nutrien bagi biota perairan, pelindung fisik, tempat pemijahan, tempat pengasuhan dan bermain bagi berbagai biota, juga menghasilkan berbagai produk yang mempunyai nilai ekonomi penting seperti berbagai jenis ikan karang, udang karang, alga, teripang dan kerang mutiara. Terumbu karang tidak hanya terdiri dari habitat karang saja, tetapi juga daerah berpasir, berbagai teluk dan celah, daerah alga dan sponge serta masih banyak lagi. Hal tersebut merupakan salah satu penyebab tingginya keragaman spesies ikan di terumbu karang. Ikan merupakan salah satu biota laut yang banyak dijumpai pada kawasan ekosistem terumbu karang. Ikan yang banyak dijumpai di kawasan ekosistem terumbu dan menggantungkan hidupnya terhadap terumbu karang ini 
dikenal dengan ikan karang. Berdasarkan peranannya ikan karang dikelompokkan menjadi tiga tipe yaitu ikan target, merupakan ikan yang menjadi target untuk penangkapan atau konsumsi. Kelompok kedua adalah ikan indikator yaitu ikan penentu kondisi terumbu karang karena ikan ini erat hubungannya dengan kesuburan terumbu karang. Kelompok ketiga adalah ikan mayor, yaitu ikan yang berperan dalam rantai makanan (Terangi, 2004).

Sebaran geografi ikan karang di Indonesia banyak ditemukan pada pulaupulau kecil. Hal ini dikarenakan wilayah perairan pada pulau-pulau kecil cenderung dalam kondisi baik. Kondisi perairan yang masih bagus pada ekosistem pulau menunjang pertumbuhan terhadap ekosistem terumbu karang. Terumbu karang merupakan suatu ekosistem sebagai tempat berasosiasi banyak biota laut salah satunya adalah ikan karang. Salah satu pulau kecil yang memiliki ekosistem terumbu karang ialah perairan laut Pulau Tikus. Pulau Tikus adalah pulau karang yang terletak sekitar 90 mil dari pantai Kota Bengkulu ke arah Samudera Hindia. Pulau Tikus merupakan pulau terdekat ke Kota Bengkulu dengan luas kawasan sekitar 2,50 ha. Pulau Tikus telah ditetapkan sebagai Taman Wisata Alam (TWA) berdasarkan Surat Keputusan Menteri Kehutanan No. 383/Kpts-II/1985 tanggal 27 Desember 1985 (BKSDA, 2006).

Pulau Tikus merupakan pulau karang kecil yang dikelilingi karang yang kaya dengan sumber daya hayati laut. Penelitian sebelumnya yang pernah dilakukan menunjukkan bahwa kondisi terumbu karang di Pulau Tikus di kategorikan bagus hingga buruk dengan penutupan karang hidup 11,46\% hingga 66,76\% (Riansyah et al., 2018). Kerusakan terjadi akibat faktor alam dan faktor yang disebabkan oleh aktifitas manusia seperti penangkapan ikan tidak ramah lingkungan. Faktor alam yang terjadi salah satunya ialah terjadinya abrasi yang sangat parah terutama pada sisi pulau yang menghadap daratan Sumatera. Banyak kematian dan kerusakan karang yang diduga terutama diakibatkan oleh naiknya suhu lingkungan yang melebihi batas normal sehingga terjadi bleaching atau pemutihan karang. Berdasarkan kondisi ini, maka diperlukan lagi penelitian mengenai kelimpahan ikan karang pada ekosistem terumbu karang di perairan Pulau Tikus.

Tujuan Penelitian ini adalah untuk mengetahui jenis dan kelimpahan ikan karang, kondisi terumbu karang serta hubungan antara ikan karang dengan terumbu karang di perairan Pulau Tikus.

\section{METODE PENELITIAN Lokasi dan Waktu Penelitian}

Penelitian ini dilaksanakan pada bulan Juni 2019. Pengambilan data berlokasi di perairan Pulau Tikus Kelurahan Marlborough Kecamatan Teluksegara Kota Bengkulu. Analisis jenis ikan karang dilakukan di Laboratorium Biologi Laut Fakultas Perikanan dan Kelautan Universitas Riau. 

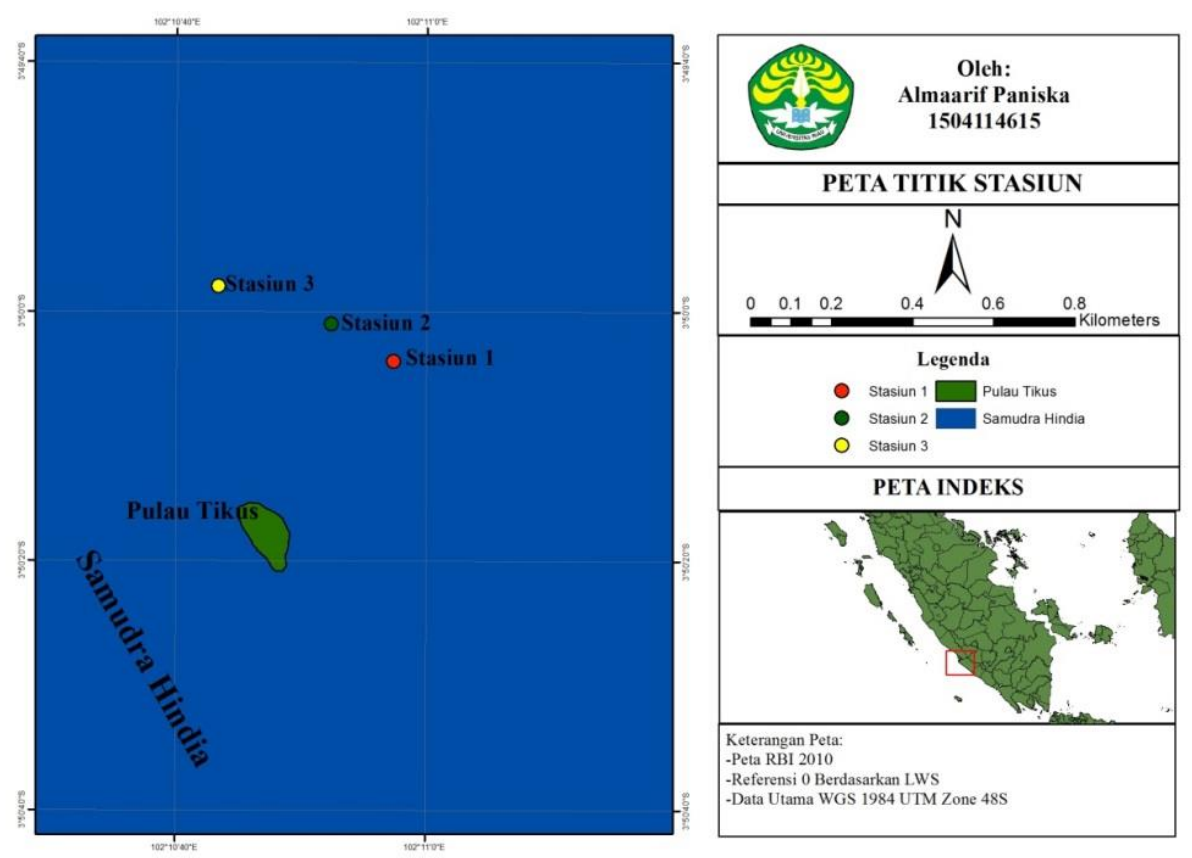

Gambar 1. Peta lokasi penelitian

\section{Penentuan Lokasi Sampling}

Metode yang digunakan dalam penelitian ini adalah metode survei. Stasiun pengamatan ditentukan secara purpossive sampling dan dipilih dengan melihat keberadaan terumbu karang yang teramati sewaktu pengamatan awal. Melalui pengamatan tersebut ditentukan tiga stasiun pengamatan. Transek dipasang secara horizontal (sejajar garis pantai) pada lokasi yang telah ditentukan. Stasiun I terletak pada titik koordinat 3050'04,75' 'LU dan 102010'57,64'BT merupakan daerah penangkapan dan menghadap ke daratan sumatera. Stasiun II terletak pada titik koordinat 3050'01,20" LU dan 102010'52,88'BT merupakan yang berada di dekat daerah aktivitas keluar masuk kapal ke daratan Pulau Tikus. Stasiun III terletak pada titik koordinat 3049'58,18' LU dan 102010'43,56" BT merupakan daerah aktivitas penangkapan nelayan dan dekat ke arah samudera.

\section{Pengukuran Kualitas Perairan}

Parameter kualitas air diukur secara langsung di lokasi penelitian (in situ) sebelum dilakukan pengambilan data ikan karang dan kondisi terumbu karang.
Parameter kualitas air yang diambil adalah suhu, salinitas, kecerahan, $\mathrm{pH}$ dan arus. Pengukuran kualitas air dilakukan sebanyak 3 kali pengulangan agar data kualitas perairan yang didapatkan tidak bias.

\section{Pengambilan Data Ikan Karang}

Pengambilan data dilakukan menggunakan metode Underwater Visual Census (UVC) dengan melakukan pemantauan secara langsung di sepanjang garis transek sepanjang 50 meter dengan areal pemantauan 2,5 meter di sisi kiri dan kanan transek garis (luas area pemantauan $250 \mathrm{~m}^{2}$ ). Identifikasi jenis ikan karang dilakukan secara langsung di lapangan dan menggunakan dokumentasi foto bawah air. Ikan-ikan yang sudah dikenali berdasarkan buku identifikasi ikan karang dicatat secara langsung diatas sabak sedangkan jenis ikan yang belum dikenali difoto atau divideokan setelah itu diidentifikasi merujuk pada Allen dan Adrim (2003); Kuiter (2002); Setiawan (2010). kelimpahan ikan karang dihitung dengan menggunakan rumus Odum (1971): 


$$
X i=\frac{x i}{A}
$$

Keterangan :

$\mathrm{Xi}=$ Kelimpahan ikan jenis ke-i

$\mathrm{xi}=$ Jumlah ikan jenis ke-i

$\mathrm{A}=$ Luas transek $\left(\mathrm{m}^{2}\right)$

Kategori kelimpahan ikan karang (Sukarno et al., 2003) sebagai berikut :

i. Sedikit: Jumlah individu ikan sepanjang transek $<50$ ekor $(<0.2$ ind $/ \mathrm{m}^{2}$ )

ii. Banyak: Jumlah individu ikan sepanjang transek 50-100 ekor (0.2-0.4 ind $\left./ \mathrm{m}^{2}\right)$

iii. Melimpah: Jumlah individu ikan sepanjang transek >100 ekor (> $0.4 \mathrm{ind} / \mathrm{m}^{2}$ )

\section{Pengambilan Data Terumbu Karang}

Pengambilan data kondisi terumbu karang dilakukan dengan menggunakan metode Line Intercept Transect (LIT) sepanjang 50 meter. Transek Garis dipasang paralel dengan kontur kedalaman yang sejajar dengan garis pantai. Pengamatan dilakukan dengan cara mencatat bentuk-bentuk pertumbuhan karang dan kelompok abiotik yang menyinggung transek sesuai dengan nilai yang tercantum pada roll meter. Pencatatan dilakukan dengan menggunakan sabak bawah air dan pensil. Kondisi terumbu karang diduga melalui pendekatan persentase penutupan karang dengan kategori kondisi dari Gomez dan Yap (1988). Rumus yang digunakan sebagai berikut:

$$
n i=\frac{l i}{L} \times 100 \%
$$

Keterangan :

$\mathrm{ni} \quad=$ Persentase penutupan karang $(\%)$

li $=$ Panjang lifeform jenis ke-i

$\mathrm{L} \quad=$ Panjang transek
Kondisi terumbu karang pada penelitian ini dikategorikan berdasarkan Keputusan Menteri Lingkungan Hidup No 4 tahun 2001 adalah sebagai berikut: Sangat Bagus : $75 \%-100 \%$, Bagus : $50 \%$ - 74.9\%, Sedang : $25 \%-49.9 \%$, Buruk: $0 \%-24.9 \%$.

\section{HASIL DAN PEMBAHASAN Kondisi Umum Lokasi Penelitian}

Pulau Tikus terletak di sebelah barat kota Bengkulu dengan jarak $10 \mathrm{~km}$ dari pusat Kota Bengkulu dan terhubung dengan Samudera Hindia. Secara geografis Pulau Tikus terletak pada tittik koordinat $3^{\circ} 50^{\prime} 17,55^{\prime \prime}$ LS dan $102^{\circ} 10^{\prime} 50,59$ ' BT. Pulau Tikus merupakan pulau karang kecil yang terletak dalam wilayah administrasi Kelurahan Marlborough, Kecamatan Teluksegara, Kota Bengkulu yang dikelilingi oleh karang yang kaya dengan sumber daya. Pulau ini memiliki tutupan terumbu karang yang relatif luas yang dimanfaatkan sebagai sumber mata pencaharian bagi nelayan sekitar karena banyaknya terdapat ikan karang yang tergolong memiliki nilai ekonomis yang tinggi (Prihantono, 2010).

Pulau Tikus memiliki luas lebih kurang 1,5 hektar dan dikelilingi hamparan terumbu karang yang sangat luas. Namun keberadaan terumbu karang di pulau ini sudah mengalami degradasi karena kerusakan yang disebabkan oleh kegiatan manusia, seperti kegiatan penangkapan ikan yang tidak ramah lingkungan. Rusaknya terumbu karang ini memberikan dampak negatif terhadap pulau, hal ini terlihat dengan semakin berkurangnya luas Pulau Tikus oleh abrasi yang berlangsung makin cepat dari tahun ke tahun (Prihantono, 2010).

\section{Parameter Kualitas Perairan}

Pengukuran kualitas air pada penelitian ini dilakukan sebanyak 3 kali pengukuran di setiap parameternya dapat dilihat pada Tabel 1. 
Tabel 1. Nilai rata-rata kualitas air di perairan Pulau Tikus pada setiap stasiun

\begin{tabular}{llccc}
\hline \multirow{2}{*}{ No. } & \multirow{2}{*}{ Parameter } & \multicolumn{3}{c}{ Stasiun } \\
\cline { 3 - 5 } & & I & II & III \\
\hline 1. & Suhu $\left({ }^{\circ} \mathrm{C}\right)$ & 30 & 30 & 29 \\
2. & Salinitas $(\%)$ & 30 & 27 & 28 \\
3. & $\mathrm{pH}$ & 8,6 & 8,5 & 8,5 \\
4. & Arus $(\mathrm{m} / \mathrm{s})$ & 0,11 & 0,09 & 0,1 \\
5. & Kecerahan $(\mathrm{m})$ & 7 & 6 & 7 \\
\hline
\end{tabular}

Berdasarkan Tabel 1, pengukuran kualitas air didapatkan hasil bahwa suhu di perairan Pulau Tikus rata-rata sama yaitu $30^{\circ} \mathrm{C}$. Salinitas tertinggi terdapat pada stasiun I yakni 30 dan terendah terdapat pada stasiun II yaitu 27. $\mathrm{pH}$ tertinggi terdapat pada stasiun I dengan nilai 8,6 dan terendah pada stasiun II dan III dengan nilai 8,5. Kecepatan arus tertinggi terdapat pada stasiun I yakni $0,11 \mathrm{~m} / \mathrm{s}$ dan terendah pada stasiun II yakni $0,09 \mathrm{~m} / \mathrm{s}$. Kecerahan tertinggi terdapat pada stasiun I dan III dengan nilai $7 \mathrm{~m}$ sedangkan terendah pada stasiun II dengan nilai $6 \mathrm{~m}$.

\section{Kelimpahan Ikan Karang}

Jumlah individu yang ditemukan pada masing-masing stasiun berbeda, dimana pada stasiun I terdapat 1.088 individu, stasiun II ditemukan sebanyak 2.091 individu, dan stasiun III sebanyak 636 individu. Kelimpahan ikan karang pada lokasi penelitian berkisar antara 0,002 $2,908 \mathrm{ind} / \mathrm{m}^{2}$. Kelimpahan ikan tertinggi terdapat pada stasiun 2 yaitu $2,908 \mathrm{ind} / \mathrm{m}^{2}$ dan kelimpahan ikan terendah terdapat pada tiap-tiap stasiun yaitu sebesar 0,002 $\mathrm{ind} / \mathrm{m}^{2}$. Sedangkan untuk kelimpahan ikan karang per titik stasiun dapat dilihat pada Tabel 2.

Tabel 2. Kelimpahan Ikan Karang pada Tiap Stasiun

\begin{tabular}{ccl}
\hline Stasiun & Kelimpahan Ikan Karang $\left(\mathbf{I n d} / \mathbf{m}^{\mathbf{2}}\right)$ & Kategori \\
\hline I & 2,18 & Melimpah \\
II & 4,18 & Melimpah \\
III & 1,27 & Melimpah \\
\hline Rata-rata & 2,54 & Melimpah \\
\hline
\end{tabular}

Pada Tabel 2 dapat dilihat bahwa kelimpahan ikan karang pada lokasi penelitian Pulau Tikus masuk dalam kategori melimpah dengan nilai rata-rata $2,54 \mathrm{ind} / \mathrm{m}^{2}$. Ikan karang dengan nilai kelimpahan tertinggi terdapat pada Stasiun II, hal ini didukung oleh banyaknya terdapat alga dibanding stasiun lainnya sehingga ketersediaan sumber makanan ikan herbivora menjadi banyak yang menyebabkan pertumbuhan ikan herbivora tersebut menjadi melimpah. Melimpahnya ikan herbivora ini juga berdampak baik bagi ikan-ikan karnivora sebagai konsumen tingkat 2. Hal ini dibuktikan dengan ditemukannya ikan karang terbanyak baik ikan herbivora maupun ikan karnivora pada stasiun II. Selain itu aktvitas manusia yang mengancam kelangsungan hidup ikan karang pada stasiun II juga tidak terlalu banyak. Ikan karang dengan nilai kelimpahan terendah terdapat pada stasiun III. Hal ini disebabkan karena posisi geografis stasiun III berhadapan langsung dengan Samudera Hindia sehingga stasiun ini memiliki kecepatan arus yang paling tinggi dibanding stasiun lainnya. Arus yang cukup tinggi ini mengganggu keberlangsungan hidup ikan-ikan karang. 
Jenis ikan yang paling sering ditemukan pada setiap stasiun pengamatan ialah ikan dari famili Pomacentridae. Menurut Adrim et al. (2012) menyatakan bahwa Pomacentridae merupakan famili ikan karang yang sering mendominasi. Ikan-ikan jenis ini memiliki ukuran tubuh yang relatif kecil dan memiliki peranan penting dalam rantai makanan. Keberadaan famili Pomacentridae sangat dipengaruhi oleh karakteristik morfologis dari substrat, bahkan beberapa spesies diantaranya cendrung menggunakan karang sebagai habitat untuk mencari makanan (Dhahiyat et al., 2003). Kelimpahan ikan famili Pomacentridae yang tinggi pada lokasi penelitian disebabkan oleh tingginya nilai persentase tutupan Dead Coral Algae, pasir, lumpur dan Turf Algae, hal ini dikarenakan Pomacentridae merupakan ikan herbivora yang sumber makanannya berupa algae dan juga berperan dalam mengontrol pertumbuhan algae (Utomo, 2016).

\section{Kondisi Terumbu Karang}

Kondisi terumbu karang pada suatu perairan sangat dipengaruhi oleh keadaan lingkungannya. Baik buruk keadaan suatu terumbu karang dapat dilihat dengan seberapa besar tutupan karang hidup dan tutupan karang mati. Tutupan terumbu karang hidup pada tiap stasiun dapat dilihat pada Tabel 4.

Tabel 4. Persentase Tutupan Karang Hidup pada Tiap Stasiun

\begin{tabular}{lll}
\hline Stasiun & Persentase Tutupan(\%) & Kategori \\
\hline I & 39,30 & Sedang \\
II & 50,94 & Baik \\
III & 46,32 & Sedang \\
\hline Rata-rata & 45,52 & Sedang \\
\hline
\end{tabular}

Persentase tutupan terumbu karang pada stasiun penelitian berkisar antara 39,30 - 50,94 \% yang termasuk dalam kategori sedang hingga baik. Dari ke tiga stasiun penelitian, stasiun II merupakan stasiun dengan tutupan terumbu karang lebih tinggi yaitu dengan persentase $50,94 \%$ dengan kategori baik. Sementara itu stasiun dengan nilai persentase tutupan paling rendah terdapat pada stasiun I dengan nilai $39,30 \%$ dengan kategori sedang. Rata-rata persentase tutupan terumbu karang pada lokasi penelitian yaitu $45,52 \%$ yang dikategorikan sedang. Pengamatan dilakukan untuk mengetahui jenis dan bentuk pertumbuhan terumbu karang yang ada pada stasiun penelitian di Pulau Tikus. Tidak semua jenis dan bentuk pertumbuhan terumbu karang dapat dijumpai pada setiap stasiun pengamatan. Adapun jenis dan bentuk pertumbuhan terumbu karang yang dapat ditemukan pada setiap stasiun pengamatan seperti jenis Coral Masive (CM), Coral Heliopora (CHL), Coral Branching (CB), Coral Mushroom (CMR), Coral Encrusting (CE), Acropora Branching (CB), Acropora Digitata (ACD) dan Acropora Submassive (CS). Selain terumbu karang ditemukan juga alga dan fauna lain berupa Soft Coral, Sponge, Turf Algae dan lain-lainnya. Pada area terumbu karang juga bisa dikaji tentang faktor abiotik lain seperti sand, rubble, silt, water dan rock.

\section{Hubungan Kelimpahan Kelimpahan Ikan Karang dengan Terumbu Karang Grafik kelimpahan ikan karang dengan kondisi terumbu karang di perairan Pulau Tikus Kota Bengkulu dapat dilihat pada gambar dibawah ini.}




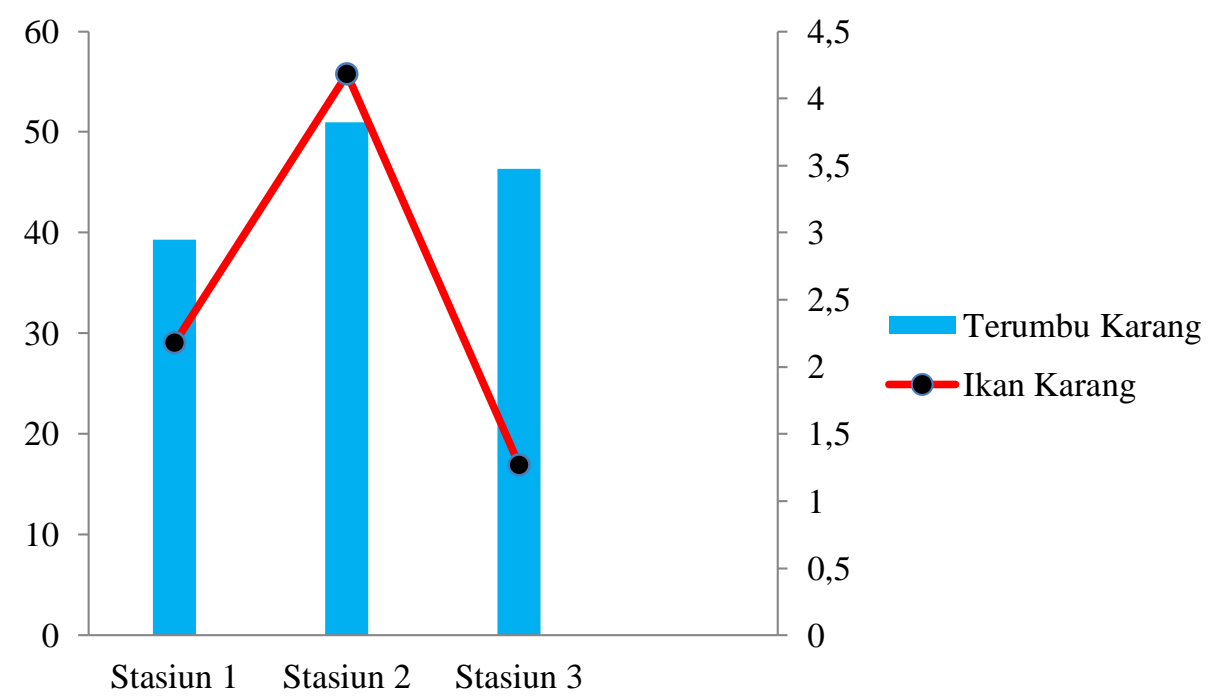

Gambar 1. Grafik Kelimpahan Ikan Karang dengan Tutupan Terumbu Karang Hidup di Perairan Pulau Tikus

Berdasarkan Gambar 1 dapat dilihat bahwa pada setiap stasiun kelimpahan ikan karang dikategorikan melimpah dengan kondisi terumbu karang dalam kondisi sedang hingga baik. Hubungan tersebut pada rantai makanan yang dimana banyaknya terdapat ikan herbivora seperti famili Pomacentridae, Acanthuridae, Apogonidae dan famili lainnya sehingga jenis ikan ini dapat mengontrol pertumbuhan alga atau tumbuhan lainnya yang dapat mengganggu pertumbuhan terumbu karang apabila keberadaan alga atau tumbuhan lainnya dalam jumlah yang terlalu banyak.

Banyaknya terdapat ikan-ikan herbivora juga menjadi keuntungan bagi jenis-jenis ikan karnivora yang melangsungkan kehidupannya disekitar terumbu karang. Selain sebagai tempat mencari makan ikan-ikan karang menjadikan terumbu karang menjadi tempat berlindung dan memijah. Pada penelitian ini ikan herbivora yang banyak ditemukan adalah famili Pomacentridae. Menurut Choat menyatakan bahwa ikan ikan herbivora mempunyai tiga peranan penting pada ekosistem terumbu karang. Pertama, sebagai konsumer dari produsen, ikan herbivora merupakan penghubung antara aliran energi yang berasal dari produsen ke konsumen tingkat 2 (karnivora). Kedua, ikan herbivora mempengaruhi penyebaran, ukuran, komposisi dan bahkan pertumbuhan dari tumbuhan di terumbu karang. Komposisi dan struktur dari tumbuhan yang berasosiasi dengan terumbu karang digambarkan melalui aktivitas ikan herbivora. Pemangsaan oleh ikan herbivora (grazing) secara substansi mengubah alga yang ada di terumbu, dimana hal ini memberika pengaruh positif maupun negatif pada karang. Ketiga, interaksi antara ikan - ikan herbivora merupakan alat dalam model demografi dan perilaku ikan karang secara keseluruhan (Purwanti, 2004).

Ikan karang merupakan sekumpulan ikan yang berada di daerah tropis dan kehidupannya berkaitan erat dengan terumbu karang (Sale, 1991 dalam Sadewo, 2006). Ikan-ikan tersebut memanfaatkan terumbu karang secara langsung maupun tidak langsung untuk kepentingan hidupnya. Menurut Nybakken (1988), ikan karang merupakan organisme yang sering dijumpai di ekosistem terumbu karang. Keberadaan mereka telah menjadikan ekosistem terumbu karang sebagai 
ekosistem paling banyak dihuni biota air. Perairan karang merupakan perairan yang cukup subur karena banyak jenis ikan karang yang berkolerasi dengan karang antara lain menujukan perilaku teritorial, pola berkembang biak dan daya jelajah yang tidak jauh dari ekosistem karang sebagai sumber persediaan makan serta tempat berlindung dari predator (Romimohtarto dan Juwana, 2001).

\section{KESIMPULAN DAN SARAN Kesimpulan}

Berdasarkan hasil penelitian yang dilakukan diperoleh kesimpulan sebagai berikut :

1. Jenis ikan karang yang dijumpai pada penelitian ini adalah sebanyak 52 jenis dan 16 famili ikan karang. Kelimpahan ikan karang pada lokasi penelitian di perairan Pulau Tikus termasuk dalam kategori melimpah. Jenis ikan yang paling banyak dijumpai yaitu dari famili Pomacentridae.

2. Hasil pengamatan menunjukkan bahwa persentase tutupan karang hidup di perairan Pulau Tikus pada stasiun I $39,30 \%$, stasiun II 50,94\%, dan stasiun III $46,32 \%$, hal ini berdasarkan baku mutu yang ditetapkan KepmenLH (2001) yaitu pada stasiun I dan III tergolong sedang (25-49,9\%), pada titik II tergolong baik $(50-74,9 \%)$.

3. Hubungan kelimpahan ikan karang dengan tutupan terumbu karang di perairan Pulau Tikus dapat dilihat dari banyaknya terdapat ikan karang yang menggantungkan kehidupannya di terumbu karang baik sebagai tempat mencari makan, berlindung maupun sebagai tempat pemijahan.

\section{Saran}

Perlunya dilakukan kajian yang lebih mendalam dan jumlah data yang lebih banyak lagi untuk melihat dampak aktivitas yang ada di sekitar perairan Pulau Tikus terhadap ekosistem terumbu karang dan komunitas ikan karang yang hidup di dalamnya.

\section{DAFTAR PUSTAKA}

1. Allen, G.R., and M. Adrim. (2003). Coral Reef Fishes of Indonesia. Zoological Studies, Volume 42(1), Pages 1-72.

2. Burhanuddin, A.I. (2011). The Sleeping Giant, Potensi dan Permasalahan Kelautan. Brilian Internasional. Surabaya.

3. Dhahiyat, Y., D. Sinuhaji., dan H. Hamdani. (2003). Struktur komunitas ikan karang di daerah transplantasi karang Pulau Pari, Kepulauan Seribu. Jurnal ikhtiologi indonesia. Volume 3(2), Pages 87-94.

4. Gomez, E.D., and H.T. Yap. (1988). Monitoring Reef Condition. (p.187-195) in R.A. Kenchington dan B.E.T Hudson (eds), Coral Reef Management Handbook. UNESCO Regional Office for Science and Tecnology for South East Asia. Jakarta.

5. KEPMENLH. (2001). Peraturan Perundang-undangan Bidang Pengelolaan Lingkungan Hidup dan Pengendalian Dampak Lingkungan, Keputusan 59 Menteri Negara No. 4 tentang Kriteria Baku Kerusakan Terumbu Karang. Jakarta. Kementerian Lingkungan Hidup.

6. Kuiter, R. H. (2002). Tropical Reef-Fishes of the Western Pacific, Indonesian and Adajacent Waters. PT. Gramedia Pustaka Utama. Jakarta.

7. Nybakken, J.W. (1988). Biologi Laut: Suatu Pendekatan Ekologis. PT. Gramedia, Jakarta. 
8. Prihantono, E. (2010). Inventarisasi dan Identifikasi Tutupan Terumbu Karang Menunjang Pengembangan Wisata Bahari di Perairan Laut Kota Bengkulu. P3MP. Bengkulu.

9. Riansyah, A., D. Hartono, dan A.B. Kusuma. (2018). Ikan Kepe-Kepe (Chaetodontidae) sebagai Bioindikator Kerusakan Perairan Ekosistem Terumbu Karang Pulau Tikus. Majalah Ilmiah Biologi Biosfera : A Scientific Journal. Volume 35 (2), Pages 103-110.

10. Romimohtarto, K. dan S. Juwana. (2001). Biologi Laut :Ilmu Pengetahuan Tentang Biologi Laut. Penerbit Djambatan. Jakarta.

11. Setiawan, F. (2010). Panduan Lapangan Identifikasi Ikan Karang dan Invertebrata Laut. Manado. Indonesia.

12. Terangi. (2004). Panduan Dasar untuk Pengenalan Ikan Karang Secara Visual Indonesia. Jakarta 